\title{
Affective Interacting Art
}

\author{
Youngmi Kim and Jongsoo Choi \\ Graduate School of Advanced Imaging Science, Multimedia, and Film, \\ Chung-Ang University, \\ 221 Huksuk-dong, Dongjak-gu, 156-756, Seoul, Korea(R.O.K) \\ \{frontier, jschoi\}@imagelab.cau.ac.kr
}

\begin{abstract}
This paper to study the potential of expressing ink-and-wash painting through interaction, and present a direction that can coincide with modern paintings by developing ink-and-wash painting from a traditional aspect through analyzing the theories and tech-niques instilled in my works. This work is an interactive visualization of an oriental cymbidium using modern technology which our oriental ancestors painted for mental training. During the old days in the orient, people used to wipe cymbidium leaves or painted cymbidium for mental training by having a cymbidium always by their side. Through the act of wiping cymbidium leaves with utmost care, a cymbidium instilled with ancient philosophical ideas is visualized.
\end{abstract}

Keywords: Ethnographic Design, mental training, Interactive art, oriental digital art, ink-and-wash painting, haptic.

\section{Introduction}

In the orient, calligraphy is utilized for the mastering of ones mind rather than just simply writing a letter or drawing a painting well. One must focus and possess a proper attitude when engaging in calligraphy because process is given more emphasis over results. This principle applies in drawing the cymbidium leaves where the participants mentality will be projected on the screen. Moreover, in order to complete a balanced cymbidium painting, cymbidium leaves must be evenly selected, and the direction and angle one wants to draw must be adjusted. This is easily linked to emotions, desires, and moods, with regenerative senses on exercise as its medium. Also, almost an unlimited expression of ones mind can be possibly conveyed by using different techniques such as direction, speed, power, and rhythm. In particular, emotional and physical safety can be obtained through aesthetic perspective, fine motor skills, hand-eye coordination, and sense of achievement. In this way, art with oriental features can be enough driving force to arouse interest and curiosity to national culture of children who will be responsible for future generations. This may be achieved by active utilization of media in line with modern perspectives. 


\section{Meaning of the Act of Drawing a Cymbidium}

The spirituality, idea, and unique characteristic of our ink-and-wash painting will be examined. This means that I intend to find the characteristic of inkand-wash painting from spirituality and express the spirituality through inkand-wash painting in my work in order to shed new light on the features of ink-and-wash painting from a modern point of view. Prior to this, I would like to help understand the act of wiping cymbidium as a means of interaction. Asians has been living with cymbidium as if it is a close friend, and an oriental cymbidium is always placed in noble places. The act of wiping each cymbidium leaves with human hands as if sweeping it off is not to maintain cleanliness but rather to uphold the spirit instilled within the cymbidium. In other words, if one's heart is troubled and there are a lot on ones mind, mental training was carried out with a careful act of wiping cymbidium leaves with a calm mind by having a cymbidium close to oneself. Once each cymbidium is wiped off, the things troubling ones mind is forgotten and ones heart is emptied. This act has great meaning as it plays a role of interacting with the cymbidium painting. While the meaning of a cymbidium painting is also similar to the act of wiping a cymbidium, it is instilled with more meaning. The artist always conducts close observation of the subject before painting it. However, the oriental method of sketching is not depicting the subject while looking at it in detail but making a sketch by memory apart from the subject. Oriental drawing technique expands the artists creative space while relying on visual memory and shape memory by making the most use of ones subjectivity and imagination breaking away from the restraint of the actual subject. What is important is drawing with creativity yet keeping several rules. The curves, and bold and thick lines of a cymbidium must be drawn, and its leaves must shake in the wind and have bones. In this work, cymbidium leaves are visualized while being divided up into leaves curved according to the angle of wiping up or down and cymbidium leaves blowing in the wind. Just like this, even in the writers work, a poem and a writing about its impression going well with the style of painting after the cymbidium and flower is painted is written in harmony and last of all, a piece of an artwork is finished by stamping a seal.

\section{Design}

When a cymbidium leaf is selected and wiped using the thumb and index finger as if sweeping it down, a cymbidium leaf is drawn one after another inside the digital frame. A flexible sensor is attached behind cymbidium leaves, and the size of an angle made while a cymbidium leaf is curved appears due to the difference in electrical current through flexible sensors. The micro controller detects this signal and converts the analog signal to a digital signal. Then, the data is sent to the PC using UART communication. The server program can detect UART output signal sent to the desktop from the micro controller and converts this data to a TCP/IP data format. As a result, this format can send this data set from 
the server to the client. Consequently, the client draws the painting according to this signal after detecting the signal.

When the angle of the curve communicated through the cymbidium leaf is big, the cymbidium leaf in the painting is drawn as curved leaves or leaves blowing in the wind. A total of 8 cymbidium leaves are drawn up, and if one breathes air into a flower after drawing a cymbidium leaf, a floral axis and flower is drawn. It takes in the strength of the breath and when it is strong, a full blossomed flower is visualized and when the breath is weak, an unblossomed flower is visualized. When the interactive work is finished, a caption or a poem that goes well with the style of the painting is written in the remaining blank space with a stamped red seal. All of these methods communicate that the painting was produced in the same way cymbidium paintings were painted in the old days. The regularity and creativity of the cymbidium painting striking a balance, writing a poem and writing which goes well with the blank space, the seal of the artist, and above all, the greatest significance is that interaction was achieved through the act of wiping the cymbidium leaves with the attitude and spirituality of the person drawing the painting.

\section{Conclusions}

This is an interactive well-being design made so children can engage in mental training physically and mentally through this artwork and naturally have an interest in the Ethnographic aspect instilled in the work. In this artwork, Education is carried out through a series of process from free selection, activity, repetition, habit to learning. This process provides special experience unobtainable in daily life, and will help setting up an educational set of values in establishing an attitude of learning during adolescence later on. To children, play doesnt simply mean playing, but means they learn sociality, emotions, reasoning, and personal relationships. Furthermore, children expressing their experience and emotions with play itself is a process of self-healing. Feeling the joy of learning, a child freely engaging in work one desires and doing an assignment with their own efforts helps display each childs intellectual ability and mentality in their individual stage of development. Therefore, it will contribute to enhancing the development of a childs emotional quotient (E.Q.).

Acknowledgments. This work was supported by Korean Research Foundation under BK21 project, Seoul R\&BD Program(TR080601), Seoul Future Contents Convergence (SFCC) Cluster established by Seoul R\&BD Program(10570). 